\title{
Niche-adaptation in plant-associated Bacteroidetes favours specialisation in organic phosphorus mineralisation
}

\author{
Ian D. E. A. Lidbury $\mathbb{D}^{1,2} \cdot$ Chiara Borsetto $\mathbb{D}^{1} \cdot$ Andrew R. J. Murphy ${ }^{1} \cdot$ Andrew Bottrill $^{1}{ }^{1} \cdot$ Alexandra M. E. Jones $^{1} \cdot$ \\ Gary D. Bending ${ }^{1} \cdot$ John P. Hammond $\mathbb{D}^{3} \cdot$ Yin Chen $\mathbb{D}^{1} \cdot$ Elizabeth M. H. Wellington ${ }^{1} \cdot$ David J. Scanlan $\mathbb{( I}^{1}$
}

Received: 24 July 2020 / Accepted: 30 October 2020 / Published online: 30 November 2020

(c) The Author(s) 2020. This article is published with open access

\begin{abstract}
Bacteroidetes are abundant pathogen-suppressing members of the plant microbiome that contribute prominently to rhizosphere phosphorus mobilisation, a frequent growth-limiting nutrient in this niche. However, the genetic traits underpinning their success in this niche remain largely unknown, particularly regarding their phosphorus acquisition strategies. By combining cultivation, multi-layered omics and biochemical analyses we first discovered that all plantassociated Bacteroidetes express constitutive phosphatase activity, linked to the ubiquitous possession of a unique phosphatase, PafA. For the first time, we also reveal a subset of Bacteroidetes outer membrane SusCD-like complexes, typically associated with carbon acquisition, and several TonB-dependent transporters, are induced during Pi-depletion. Furthermore, in response to phosphate depletion, the plant-associated Flavobacterium used in this study expressed many previously characterised and novel proteins targeting organic phosphorus. Collectively, these enzymes exhibited superior phosphatase activity compared to plant-associated Pseudomonas spp. Importantly, several of the novel low-Pi-inducible phosphatases and transporters, belong to the Bacteroidetes auxiliary genome and are an adaptive genomic signature of plantassociated strains. In conclusion, niche adaptation to the plant microbiome thus appears to have resulted in the acquisition of unique phosphorus scavenging loci in Bacteroidetes, enhancing their phosphorus acquisition capabilities. These traits may enable their success in the rhizosphere and also present exciting avenues to develop sustainable agriculture.
\end{abstract}

\section{Introduction}

Flavobacteriaceae belong to the phylum Bacteroidetes and are dominant members of plant/soil and ocean microbiomes [1-5]. In the plant microbiome (rhizosphere, endosphere

These authors contributed equally: Ian D. E. A. Lidbury, Chiara Borsetto.

Supplementary information The online version of this article (https:// doi.org/10.1038/s41396-020-00829-2) contains supplementary material, which is available to authorized users.

Ian D. E. A. Lidbury

I.lidbury@ sheffield.ac.uk

1 School of Life Sciences, University of Warwick, Gibbet Hill Road, Coventry, UK

2 Department of Animal and Plant Sciences, University of Sheffield, Sheffield, UK

3 School of Agriculture, Policy, and Development, University of Reading, Earley Gate, Whiteknights, Reading, UK and phyllosphere), the abundance of Flavobacteriaceae and other members of the Bacteroidetes phylum is generally orders of magnitude greater than that of the surrounding bulk soil [2, 3, 6, 7]. Flavobacteriaceae typically represent $5-65 \%$ of the microbial community associated with various agriculturally important crops [8] and exhibit functionally important effects on plant health [8-11]. In Barley, 25\% of the isolates obtained from the rhizosphere were related to Flavobacteriaceae and these contributed almost $50 \%$ of the potential microbial P-turnover [12]. In contrast to other important plant-associated microbiota [13-16], the genetic traits responsible for the success of Flavobacteriaceae in the plant microbiome, including their phosphorus acquisition strategies, have not been resolved.

In ocean and animal microbiomes, Bacteroidetes are key regulators of carbon cycling, and thus microbiome functioning, due to their enhanced ability to degrade complex algal and plant-derived polysaccharides [4, 5, 17]. Terrestrial Flavobacteriaceae have also been predicted to degrade plant-derived glycans due to the high number of glycanspecific hydrolytic enzymes encoded in their genomes 
$[8,18]$. Polysaccharide degradation in Bacteroidetes utilises specialised gene clusters, termed polysaccharide utilisation loci (PULs) [19]. A prominent feature of PULs includes a two-component outer membrane (OM) transport system-

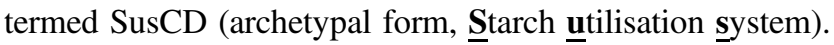
SusC is a transmembrane TonB-dependent transporter (TBDT) and SusD is the ligand-binding lipoprotein cap [20]. The specificity of the SusCD-like-complexes allows Bacteroidetes to grow on a variety of plant- [21, 22] algal[23] and fungal-derived polysaccharides [24, 25]. The latter category includes the sole example of an entire PUL characterised in Flavobacterium.

For all biota on Earth, $\mathrm{P}$ is an essential macronutrient and its availability directly affects the global carbon cycle as well as governing global crop production [26-30]. Modern agriculture massively relies on the use of unsustainable chemical fertilisers, which has now created an emerging global phosphorus crisis $[26,31]$. In soils, $P$ exists in many immobilised organic and inorganic complexes whilst only a small fraction $(<1 \%)$ exists in solution as orthophosphate (Pi) [32-34]. The rate plants take up labile Pi into their roots far exceeds the rate at which diffusion can replenish soil Pi surrounding the roots [32, 33]. This creates localised regions of Pi-depletion at the soil-plant interface (a region commonly referred to as the rhizosphere) [35]. Organic P $\left(\mathrm{P}_{\mathrm{o}}\right)$ often accounts for the majority of total $\mathrm{P}$ in soils and soil microorganisms play a key role in solubilising this fraction before it becomes available to plants $[33,34,36]$. However, rhizosphere microbes also contribute to the immobilisation of labile $\mathrm{Pi}$, thus competing with plants for $\mathrm{P}$ $[32,37]$. Therefore, developing a greater understanding of soil microbial P dynamics at the soil-root interface is critical for improving sustainable agriculture [33, 38, 39] and improving models regarding plant's efficiency to sequester anthropogenic $\mathrm{CO}_{2}$ emissions [29, 30].

Bacteria have evolved numerous strategies to overcome environmental Pi scarcity, which are almost exclusively regulated by a two-component system, usually referred to as PhoBR (PhoB, DNA binding response regulator; PhoR, transmembrane histidine kinase) [13]. Several P-scavenging strategies are common to almost all bacteria, the most common being possession of a high affinity Pi transport system, PstSABC, as well as inducing periplasmic and OM-bound phosphatases $[13,15,40]$. Several studies have shown that Bacteria predominantly secrete non-specific alkaline phosphatases (APases) comprising three distinct forms (PhoA, PhoD and PhoX) whilst a few cultured strains secrete acid phosphatases (AcPases, class I, II and III) in response to Pi limitation [13-16, 41]. However, recent evidence from genomic and metagenomic datasets suggest only half possess these characterised P-mobilising enzymes [42].

Here, we isolated Bacteroidetes strains from the rhizosphere of the economically important crop Brassica napus
L. (Oilseed Rape, OSR), grown under field conditions, to determine the Pi-mobilisation potential of this enigmatic phylum. After initially observing atypical constitutive phosphatase activity in all our Bacteroidetes isolates we performed a comprehensive multi-layered omics approach to identify the genetic loci responsible for this unique trait. In doing so we also discovered Flavobacterium possess an extremely high potential for transforming rhizosphereassociated $\mathrm{P}_{\mathrm{o}}$ through unique uptake and degradation systems.

\section{Materials and methods}

\section{Isolation and growth medium used for cultivating Bacteroidetes}

Flavobacterium johnsoniae DSM2064 (UW101) was purchased from the Deutsche Sammlung von Mikroorganismen und Zellkulturen (DSMZ). Flavobacterium sp. F52, a bell pepper rhizobacterium [43] and Flavobacterium sp. L0A5, a desert plant rhizobacterium (Cytryn, unpublished data) were both kindly donated from the Cytryn Lab, Agricultural Research Organisation, Israel. Strains were routinely maintained on casitone yeast extract medium (CYE) [44]. Pseudomonas strains, previously described in [15], were maintained in Luria-Bertani medium. To isolate all other strains a modified R2A medium developed by [45] was used. Cyclohexamide $\left(100 \mathrm{mg} \mathrm{L}^{-1}\right)$ and Kanamycin $\left(40 \mathrm{mg} \mathrm{L}^{-1}\right)$ were added to reduce fungal and non-Flavobacterial growth, respectively. To investigate the effect of Pi-depletion on the Flavobacterium strains, each was grown $(n=3)$ in a Minimal A medium adapted from [15]. Carbon source, glucose $3.6 \mathrm{~g} \mathrm{~L}^{-1}$ and $20 \mathrm{mM}$ Bis/Tris buffer $\mathrm{pH} 7.2$ was used instead of HEPES and $\mathrm{KH}_{2} \mathrm{PO}_{4}$ added to a final concentration of either $50 \mu \mathrm{M}$ or $1.4 \mathrm{mM}$. A final concentration of $\mathrm{NH}_{4} \mathrm{Cl} 1$ $\mathrm{mM}, \mathrm{FeCl}_{2} 10 \mathrm{mg} \mathrm{L}^{-1}$ and $\mathrm{KH}_{2} \mathrm{PO}_{4} 1.4 \mathrm{mM}$ was used for the $\mathrm{N}$-limited medium. A final concentration of $\mathrm{NH}_{4} \mathrm{Cl} 8.4 \mathrm{mM}$ and $\mathrm{KH}_{2} \mathrm{PO}_{4} 1.4 \mathrm{mM}$ with no $\mathrm{Fe}$ added was used for the $\mathrm{Fe}$ limited medium. The control contained an excess of all nutrients. Cells were harvested at mid exponential phase $\left(\mathrm{OD}_{600 \mathrm{~nm}}\right.$ 0.4-0.8) after 16-20 h.

\section{Isolation of Bacteroidetes}

For isolation, two field trials growing Brassica napus L. (OSR) were utilised. The first was located at Warwick Crop Centre (April 2017), University of Warwick, Wellesbourne and the other was located at Sonning Farm, University of Reading (Sept. 2017). Samples were collected during the flowering stage at Warwick Crop Centre and during the four-leaf stage at Sonning Farm. Plants were removed from soil and shaken to remove all loosely adhering soil. Roots 
containing tightly adhering soil were cut and washed (shaken vigorously) in $10 \mathrm{~mL}$ phosphate-buffered saline solution to remove rhizosphere soil. A serial dilution of the resulting soil solution was set up and plated onto either modified R2A or CYE. Individual colonies were picked and sub-cultured prior to identification by $16 \mathrm{~S}$ rRNA gene analysis.

\section{Genome sequencing of the Flavobacterium isolates}

The OSR isolates were grown on CYE and cells were collected from plates by scraping off bacterial colonies. Cells were then sent to the Microbes NG unit (https:// microbesng.uk/) at the University of Birmingham and data are deposited in the European Nucleotide Archive database. For assistance, amino acid sequences for the complete CDS profile of all newly isolated strains are attached to the Tables file (S16-S22).

\section{Quantification of phosphatase activity}

The protocol was adapted from Lidbury et al. [15]. Briefly, $0.5 \mathrm{ml}$ cell cultures $(n=3)$ for both Pi-replete and Pideplete growth conditions were directly incubated $\left(30^{\circ} \mathrm{C}\right.$ at $160 \mathrm{rpm}$ ) with $4 \mathrm{mM}$ para-nitrophenyl phosphate ( $p$ NPP) using a $100 \mathrm{mM} p$ NPP stock solution in $20 \mathrm{mM}$ Tris $\mathrm{HCl}$, $\mathrm{pH}$ 7.2. The $\mathrm{pH}$ of the reaction mixture was equivalent to the culture medium and was not altered by addition of $p$ NPP. The reaction was stopped using $2 \mathrm{mM} \mathrm{NaOH}$ once a colour change was detected. A colour change typically occurred within 5-20 min unless activity was very low (Pseudomonas spp.), in which case reactions were stopped after $1 \mathrm{~h}$. All raw absorbance values were lower than A405nm 1. For each strain and growth condition, A405nm measurements were corrected by subtracting $\mathrm{A}_{405 \mathrm{~nm}}$ measurements for reactions immediately stopped with $\mathrm{NaOH}$. Normalisation against the culture optical density $\left(\mathrm{OD}_{600}\right)$ was performed and the rate was calculated and expressed $\mathrm{h}^{-1}$. A standard curve for para-nitrophenol was generated using a range of known concentrations $(0.25,0.5$, $1,2,4 \mathrm{mM})$. A qualitative plate assay using the substrate XP (5-Bromo-4-chloro-3-indolyl phosphate) was also established to confirm phosphatase activity.

\section{Multi-omics analysis of nutrient-limited $F$. johnsoniae}

To capture the transcriptome, RNA was extracted using the RNeasy Mini Kit (QIAGEN) following the manufacturer's instructions. RNA-seq library preparation, sequencing and standard bioinformatics analysis were performed by Novogene according to the company pipeline. A full description of the method is provided in Supplementary materials. To capture the cellular proteome $(\mathrm{CP})$ and exoproteome (XP) we followed the method described by Lidbury et al. [15]. A full description of the method is provided in Supplementary materials.

\section{Protein fractionation of the soluble $F$. johnsoniae CP}

Cells (500 ml culture) were grown under Pi-deplete conditions and harvested as already described above. Detailed methodology for all three fractionation steps are described in Supplementary materials. An initial fractionation step was performed using size-exclusion chromatography via gel filtration. Fractions were assayed for phosphatase activity as described above. 1D-SDS PAGE analysis revealed the active fractions (peaks 1 and 2) contained a complex mixture of proteins, therefore a second fractionation step was performed on each peak. Both phosphonate-affinity chromatography (peak 1) and anion-exchange (Na gradient) chromatography (peak 2) was performed prior to activity assays and peptide identification.

\section{Comparative genomics analyses}

The online platform Integrated Microbial Genomes \& Microbiomes server at the Joint Genome Institute (IMG/ JGI) was used to perform the majority of comparative genomics analyses described in this study. Genomes were stored in Genome sets and BLAST searches (Min. similarity $30 \%, E$-value $\mathrm{e}^{-50}$ ) were set up using the 'jobs function'.

To determine genome completeness of the OSR isolates, orthologs of core metabolic genes [46] were identified in DSM2064 and F52 using IMG/JGI. Local BLASTP was then performed on the OSR isolates and LAO-5 using DSM2064 orthologs as the query. To generate and annotate ORFs, a local version of the Prokka pipeline [47] was performed. Comparative genomic analyses of the Flavobacterium strains used in this study were performed using a local version of BLAST + . In most cases ORFs found in DSM2064 were used as the query, unless this strain lacked a given ORF. A relatively high stringency was set $\left(\mathrm{e}^{-90}\right)$. Any hits with low scores were manually checked to determine whether they were true orthologs or paralogs.

Structural homology analysis of the various uncharacterised Pi-acquisition proteins was performed using the online servers for SWISS-model homologue analysis (https://swissmodel.expasy.org/) and Protein Homology/ analogy Recognition Engine Version 2.0 (PHYRE2, http://www.sbg.bio.ic.ac.uk/ phyre2/html/page.cgi?id= index). All searches were performed using the default parameters.

Phylogenetic analyses were performed using IQ-Tree [48] using the parameters -m TEST -bb 1000 -alrt 1000. Thus, the most suitable model was chosen by the software. 


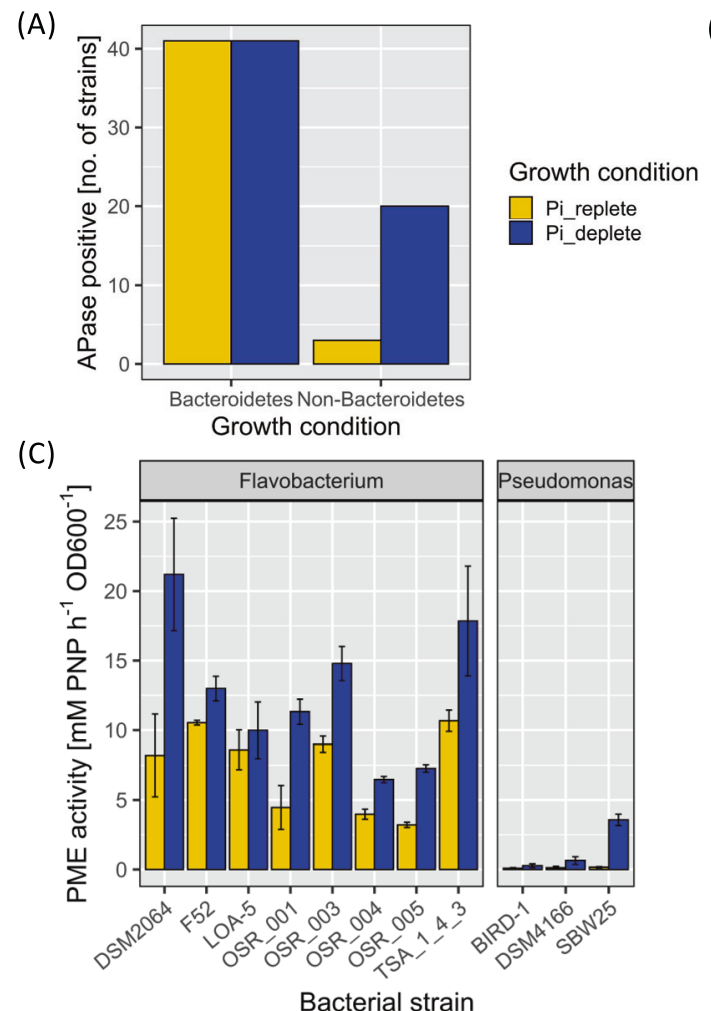

Fig. 1 Phosphomonoesterase activity observed in plant-associated Bacteroidetes. A Phosphatase (monoesterase) activity of Bacteroidetes $(n=42)$ and non-Bacteroidetes strains $(n=20)$ isolated from the rhizosphere of field-grown Oilseed Rape (OSR) grown on glucose as the carbon source. B Phylogenetic analysis of Flavobacterium isolates using a multi-locus approach with ten single-copy core genes (as

Evolutionary distances were inferred using maximumlikelihood analysis. Relationships were visualised using the online platform the Interactive Tree of Life viewer (https://itol.embl.de/).

All statistical analyses and data visualisation were performed using the vegan, ggplot2, ggfortify, tidyr, plyr, serration packages in Rstudio (1.2.5033).

\section{Results}

\section{Root-associated Bacteroidetes display 'unusual' constitutive and strong inducible phosphatase activity}

Using a selective medium [43], we isolated numerous Bacteroidetes strains from field-grown OSR rhizosphere soil (Two locations; Sonning Farm, Reading, UK and Warwick Crop Centre, Wellesbourne, UK). Most isolated Bacteroidetes were related to Flavobacteriaceae and to a lesser extent Sphingobacteriaceae (Fig. S1). In addition, several kanamycin-resistant non-Bacteroidetes strains were still isolated. A random subset of 42 Bacteroidetes isolates and 20 previously described by [18]). Evolutionary distances were inferred using the maximum-likelihood method in MEGA 7. C Phosphomonoesterase activity of whole-genome-sequenced OSR strains, nonOSR Flavobacterium strains and three Pseudomonas rhizosphere strains grown on glucose as the carbon source. Results are the mean of triplicate assays and error bars denote \pm standard deviation.

non-Bacteroidetes (predominantly Gammaproteobacteria) were screened for phosphatase (phosphomonoesterase [PME]) activity (Fig. 1A). Strikingly, all Bacteroidetes isolates tested exhibited constitutive phosphatase activity i.e. irrespective of Pi availability, in contrast to just $3 / 20$ nonBacteroidetes isolates. All OSR isolates exhibited inducible phosphatase activity when grown under Pi-deplete conditions.

Five OSR rhizosphere strains, representing the breadth of terrestrial Flavobacterium diversity (Fig. 1B), were selected for further analysis of their in vitro PME activity. For comparison, the model soil bacterium Flavobacterium johnsoniae DSM2064 (hereafter DSM2064) [42], two previously-isolated rhizosphere strains Flavobacterium sp. F52 (F52) and Flavobacterium sp. L0A5 (LOA5) [41], and three plant-growth promoting Pseudomonas spp. strains $[15,49]$ were also assayed. After overnight growth on glucose as a carbon source, due to the conversion of excess sugar to organic acid, the $\mathrm{pH}$ of the medium for all strains dropped to $\mathrm{pH} 6.1 \pm 0.4$. Whilst the strength of both the constitutive and inducible phosphatase activity varied, all Flavobacterium strains exhibited constitutive activity (Fig. 1C). The Pseudomonas isolates only possessed inducible phosphatase activity, consistent with their possession 
of well-known Pi-sensitive phosphatases [15]. Furthermore, Flavobacterium inducible phosphatase activity was far superior to the Pseudomonas strains (Fig. 1C).

\section{Phosphate depletion elicits a major regulatory response in Flavobacterium johnsoniae}

To determine the phosphatases responsible for generating both the inducible and constitutive phosphatase activity, the model bacterium DSM2064 was challenged with Pi-limiting growth conditions and subjected to both transcriptomic and proteomic analyses. The latter comprised analysis of both CP and XP. Iron $(\mathrm{Fe})$ and nitrogen $(\mathrm{N})$-limiting growth conditions were also established to act as additional controls in addition to the high $\mathrm{Pi} / \mathrm{Fe} / \mathrm{N}$ controls (Fig. 2). DSM2064 exhibited a clear transcriptomic response to all three growth-limiting conditions, but the proteomic response was most pronounced during Pi-depletion (Fig. 2A). Specific genes and gene clusters were differentially expressed under the three distinct nutrient-limiting growth conditions (Fig. 2B, C, Tables S1 and S2). Fe-regulated and N-regulated genes and their proteins are presented in Tables S1 and S2. Pi-depletion resulted in the greatest number of upregulated transcripts $\left(\log _{2} \mathrm{FC}>4\right.$, $Q$ value $P<0.05 ; \mathrm{Pi}=95$ [avg. $\mathrm{FC}=6.54$ ], $\mathrm{N}=57$ [avg. $\mathrm{FC}$ $=4.95$ ], $\mathrm{Fe}=47$ [avg. $\mathrm{FC}=7.69$ ]) and corresponding proteins. This included an unusually high number of genes predicted to encode PMEs and phosphodiesterases (PDEs) (Table 1). Whilst several P-responsive loci have no known function, their tight repression under $\mathrm{N}$ and $\mathrm{Fe}$ limitation suggests these unique proteins play a primary role in scavenging $\mathrm{P}$. These uncharacterised low-Pi-inducible loci included four hypothetical lipoproteins (Fjoh_0546, Fjoh_0549, Fjoh_3856, Fjoh_4889), two of which were located downstream of low-Pi-inducible TBDTs. Significantly, three of these hypothetical lipoproteins represented a major fraction of the Pi-deplete XP (Table 1 and Fig. 2C). Whilst some OM-transport systems related to TBDTs and SusCD-like complexes were either constitutively expressed or induced in response to Fe-depletion (archetypal function), we identified three TBDTs and two SusCD-like complexes (hereafter termed Phosphate utilisation system (Pus)), that were induced under Pi-depletion only (Table 1 and Fig. 2C). Interestingly, we also observed the expression of a nonribosomal peptide cluster in response to Pi-depletion whose expression appeared to be post-transcriptionally regulated (Fig. 2C).

\section{F. johnsoniae DSM2064 expresses a high number of phosphatases}

Further in silico analyses of the putative PMEs and PDEs revealed DSM2064 has a very high potential to mineralise $\mathrm{P}_{\mathrm{o}}$ (Table 1). Some were low-Pi-inducible whilst others

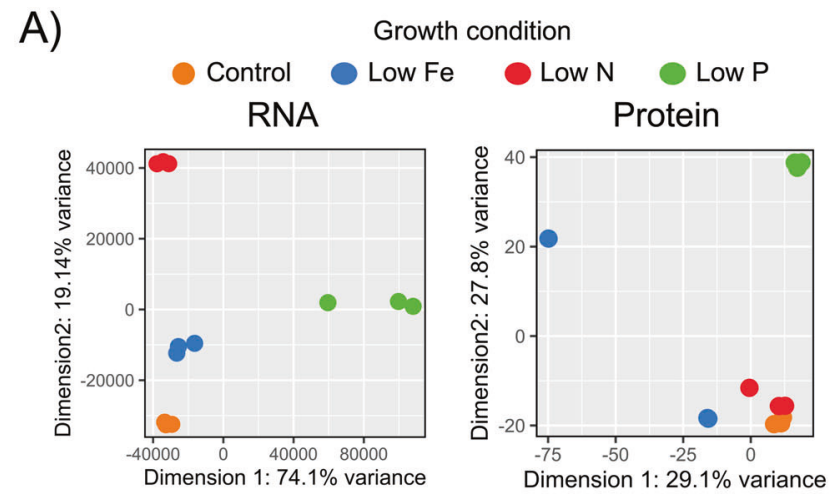

B)

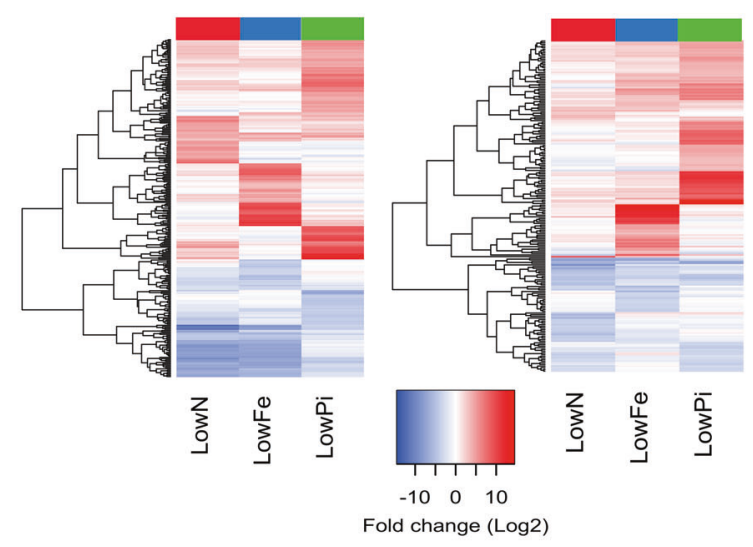

C)

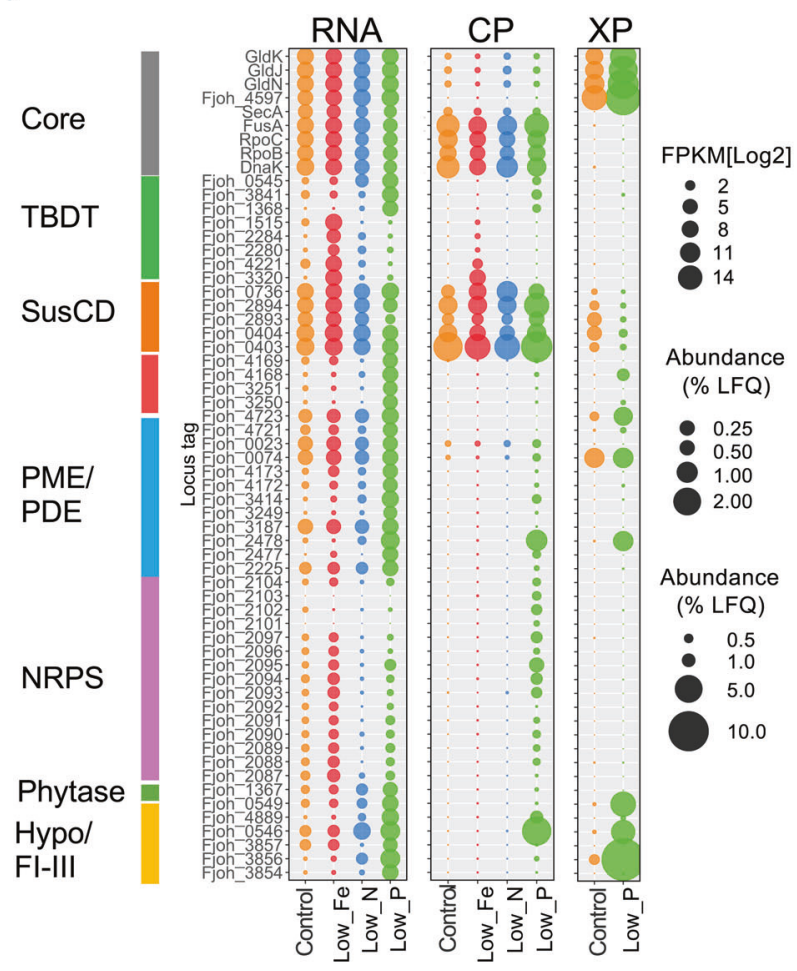

were constitutively expressed, suggesting a constant reliance on P-acquisition from Po. We previously demonstrated that PME activity in Pseudomonas spp. was produced by 
4 Fig. 2 Transcriptomic and proteomic analyses of $F$. johnsoniae (DSM2064) in response to growth under different nutrient stress conditions. A Multidimensional scaling (euclidean distance) analysis of RNA and protein content in DSM2064 sampled after $18 \mathrm{~h}$ growth. One Fe replicate contained much less protein, hence its separation in the multidimensional scaling. B Selected genes and corresponding proteins showing significant $(T$ test $=P<0.05$, adjusted $\mathrm{FDR}=0.05$ ) differential expression/abundance from the control growth condition. C The relative abundance of selected genes in the transcriptome (\% abundance based on FPKM [ $\left[\log _{2}\right]$ ) and corresponding proteins (\% abundance based on raw label-free quantitative values) detected in either the total cellular proteome (CP) or exoproteome (XP). Genes/ proteins were categorised into various functional guilds i.e. Core/ housekeeping (grey), TonB-dependent transporter (TBDT, green), SusCD-like transport system (red), phosphatase-like enzymes (sky blue), a non-ribosomal secondary metabolite cluster (NRPS, purple), phytase (dark green), hypothetical lipoproteins, FI/II/III (orange). Results in (B) and (C) are the mean of triplicate cultures.

non-cytoplasmic PMEs, indicating $p$ NPP does not cross the cytoplasmic membrane [15, 50]. Most PMEs and PDEs were predicted to possess $\mathrm{N}$-terminal signal peptide sequences (periplasmic) and a subset of these also possessed predicted lipobox sequences (OM-anchored). Four putative PMEs likely contributed to the observable PME activity in DSM2064. Sequence and structural homology searches revealed two predicted periplasmic PMEs (Fjoh_3187, Fjoh_3249) were related to PhoA [51] (Fig. S2) and one predicted OM-anchored PME (Fjoh_2478) was distantly related to PhoX [16] (Fig. S3). Fjoh_3249 (PhoA1) Fjoh_3187 (PhoA2) had varied expression profiles and neither were abundant in the CP or XP (Table 1 and Fig. 2C). Fjoh_2478 was heavily transcribed and represented a major component of the XP during Pi-depletion (Table 1 and Fig. 2C). 9/10 key residues found in the PhoX active site were conserved in Fjoh_2478 (Fig. S3). However, phylogenetic analysis revealed Flavobacterium PhoX is distinct from the previously defined PhoXI or PhoXII clades [16] (Fig. S4). Indeed, the predicted active site architecture for DSM2064 PhoX and surface electrostatic potential are quite different to previously characterised PhoX (Fig. S3), suggesting a potential difference in enzyme kinetics, $\mathrm{pH}$ range and substrate preference [52]. Similar to Pseudomonas spp. OM-anchored PMEs [45], we hypothesised Fjoh_2478 contributed most of the inducible PME activity in DSM2064. The fourth putative PME (periplasmic), Fjoh_0023, was expressed in all growth conditions, irrespective of Pi availability (Fig. 2C and Table 1). This predicted periplasmic phosphatase has high sequence (44\% identity, $\mathrm{e}=5^{\mathrm{e}-159}$ ) and structural homology (Fig. S5) to the Pi-irrepressible phosphatase PafA, identified in the human opportunistic pathogen Elizabethkingia (formerly Chryseobacterium) meningosepticum [53].

PhoA, PafA and PhoX all mineralise $p$ NPP in vitro $[16,40,50,53]$. Therefore, to determine if these four putative
PMEs contributed to PME activity in DSM2064, the soluble $\mathrm{CP}$, extracted from cells grown under Pi-depletion, was fractionated prior to screening for PME activity. Two major peaks of PME activity were detected across the fractionated $\mathrm{CP}$ and both of these were subjected to a further fractionation step (See Supplementary methods and Fig. S6). For peak 1, Fjoh_0023 was the major protein whose abundance was positively correlated with PME activity $(P<0.01$, Fig. S6, Table S4). For peak 2, PhoA2 (Fjoh_3187) was the second most abundant protein detected in the active fraction, whilst another inducible periplasmic APase Fjoh_2225 (Table 1) was also detected, albeit at a lower abundance (Fig. S6 and Table S5).

\section{F. johnsoniae expresses distinct polysaccharide utilisation loci-type gene clusters in response to Pi-depletion}

Bacteroidetes are best-known for their possession of numerous PULs, typified by the presence of susCD-like complexes, enabling them to efficiently acquire and degrade complex polymeric carbon molecules $[8,19]$. We identified four gene clusters, heavily induced during Pi-depletion, that are predicted to share similar mechanisms with traditional PULs for OM-binding, OM-transport, and periplasmic degradation of organic substrates (Fig. 3). The first two, labelled PUSI and PUSII, possessed the two low-Piinducible PusCD complexes, PusCD1 (Fjoh_4168/9) and PusCD2 (Fjoh_3250/1) (Fig. 3). Unlike traditional PULs that contain hydrolytic enzymes found in the CAZy database [22, 54], PUSI and PUSII were co-localised with two of the differentially expressed periplasmic PDEs (PUSI, Fjoh_4172; Fjoh_4173), or the PME, PhoA1 (PUSII, Fjoh_3249). PhoA1 is predicted to possess an additional domain (pf13653), unique for PhoA, potentially extending its substrate range to target specific phosphodiesters (Table 1). In agreement, PhoA1 is predicted to have a more accessible active site, a prerequisite for catalysis of phosphodiesters [55] (Fig. S2).

Two more PUS gene clusters (here labelled PUSIII and PUSIV) were also identified. PUSIII contained a hypothetical lipoprotein, hereafter termed F(form)I, encoded by fjoh_3856, that was the most differentially transcribed gene and the most abundant exoprotein (18.7\%) suggesting an important role in combatting Pi-depletion (Table 1 and Fig. 2C). The remaining ORFs in PUSIII encoded a TBDT/SusC-like porin, various OM hypothetical proteins, an OM protease and a putative cytoplasmic PDE, all of which were induced in response to Pi-depletion (Fig. 3). In PUSIV, the ORF encoding another related hypothetical lipoprotein, hereafter termed $\mathrm{F}$ (form)II, is co-localised in a Pi-sensitive gene cluster containing phoBR and ORFs encoding other heavily expressed proteins (Fig. 3). FI, FII and a third related orphan lipoprotein, termed FIII, all 


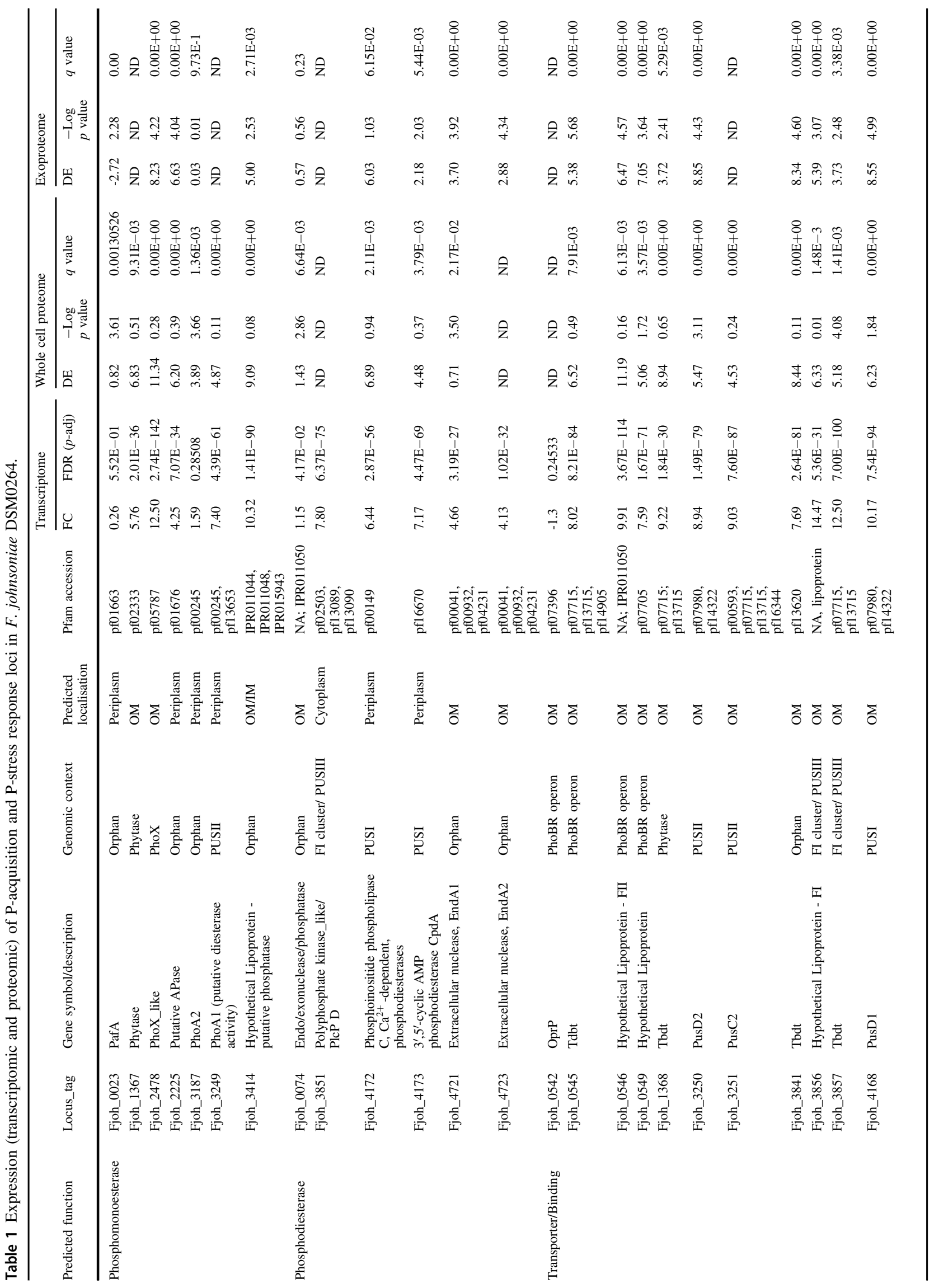




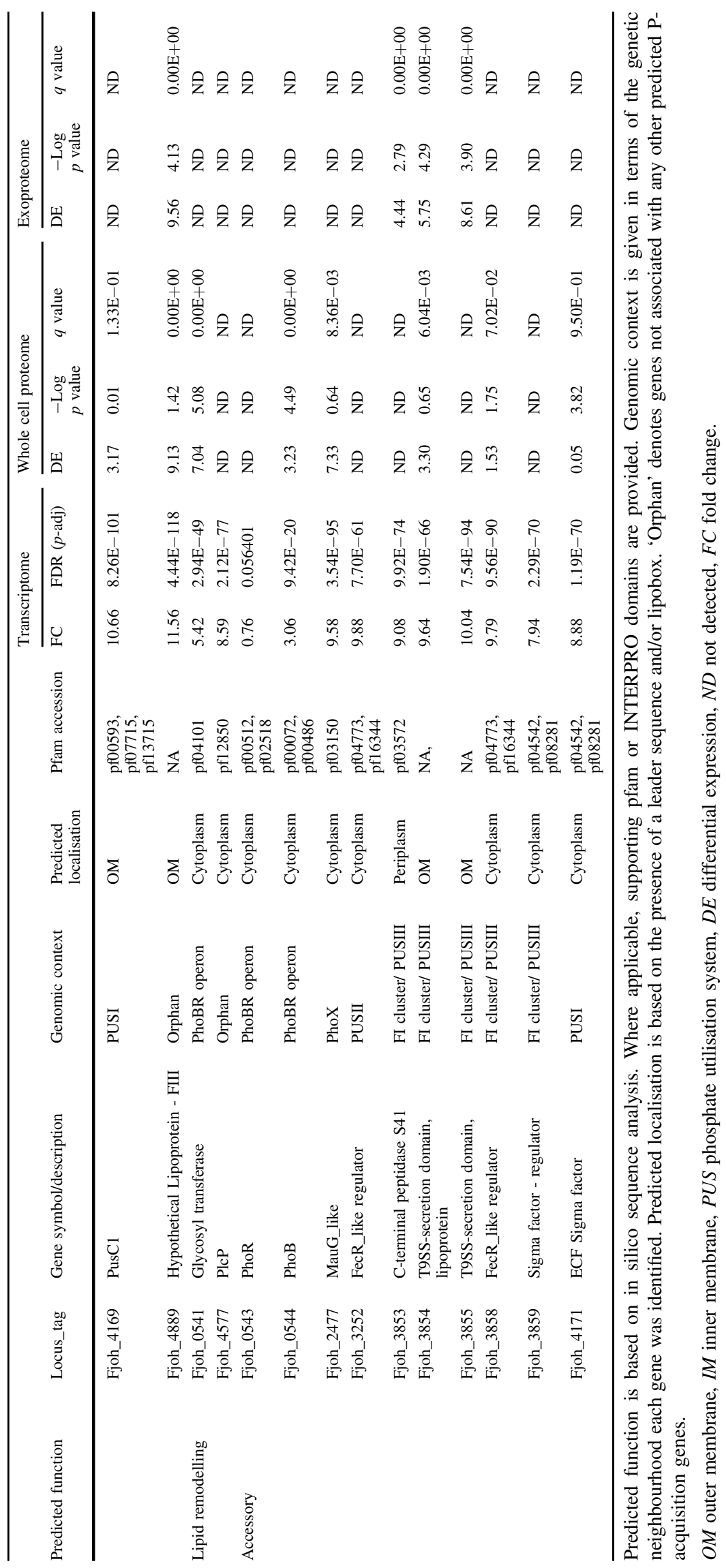




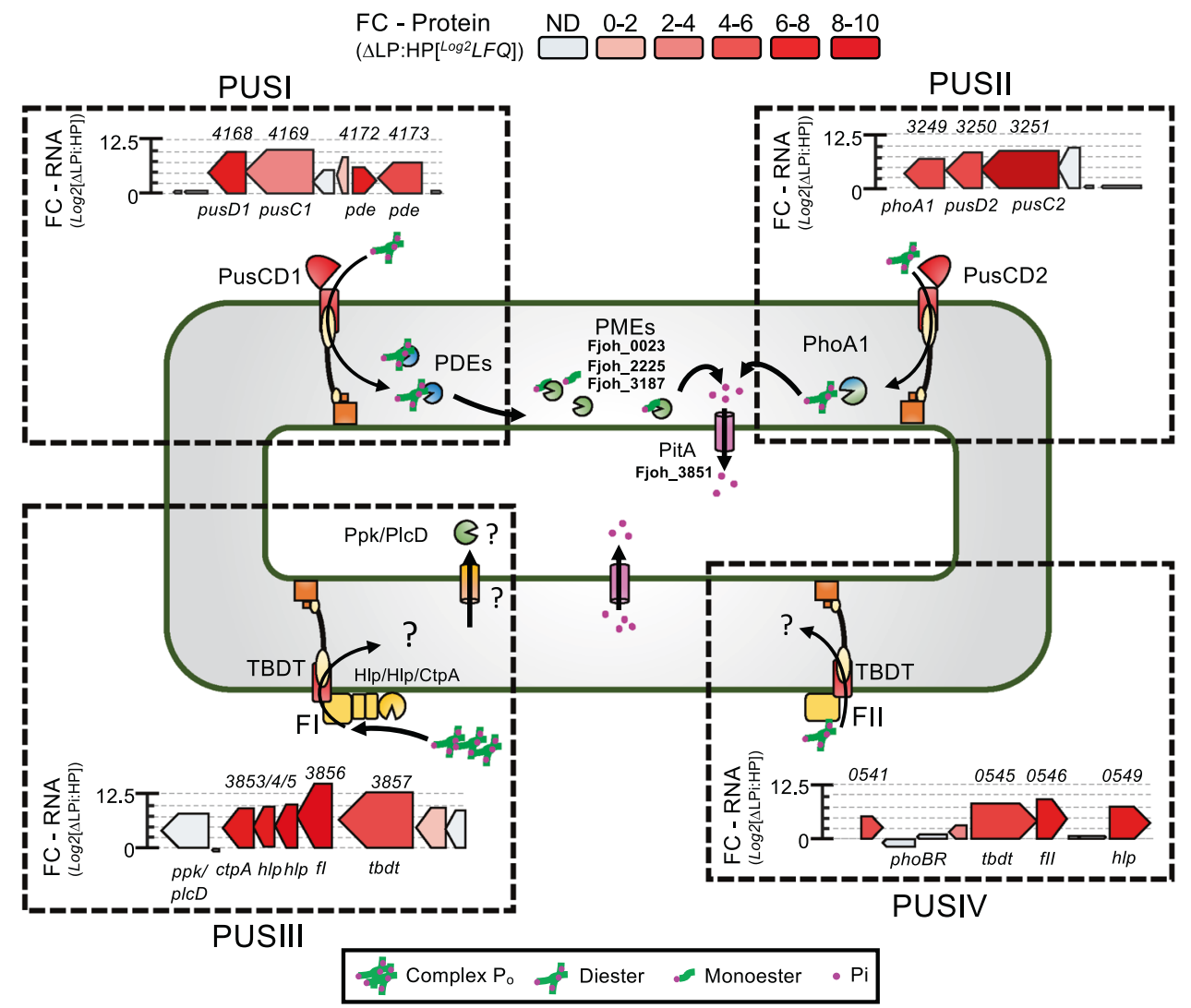

Fig. 3 Expression of putative Pi-sensitive polysaccharide utilisation loci in $\boldsymbol{F}$. johnsoniae. Intergration of transcriptomic ( $y$ axis on genetic neighbourhood maps) and proteomic data (colour gradient on genetic neighbourhood maps) with in silico function prediction/cellular location used to generate a proposed model for the newly identified Phosphate utilisation systems in Flavobacterium johnsoniae DSM2064. Locus tags for selected ORFs are given, omitting 'fjoh_'. Results shown are the mean of triplicate cultures in each growth

appear to be related to each other (Fig. S7) and share modest sequence homology (31-36\% identity, 50-54\% coverage) with a low-Pi-inducible lipoprotein of Caulobacter crescentus that has an accessory role in producing phosphatase activity [56]. Furthermore, structural homology modelling revealed these proteins may have a role in binding or hydrolysing plant glycans or other complex plant-cell wall molecules, similar to that of the Aspergillus niger polygalacturanase [57] (Fig. S7). Combining all these data, it is clear that DSM2064 invests a large amount of cellular resources into expressing several PUS gene clusters that we predict target $\mathrm{P}_{\mathrm{O}}$ molecules.

\section{The unique Flavobacterium PHO regulon is largely conserved across plant-associated isolates}

To better determine how important these unique Piacquisition loci are for root-associated Flavobacterium, we performed whole-genome sequencing and exoproteomics on the OSR rhizosphere strains previously tested for their condition. Abbreviations: FC fold change, LFQ label-free quantification, PusCD phosphate utilisation system transporter complex - SusC forms the transmembrane pore and SusD is the cell-surface ligandbinding protein, FI/FII, hypothetical lipoproteins with homology to polygalacturanase, Ppk/PlcD polyphosphate kinase/phosphatidylinositol phospholipase-like, PME phosphomonoesterase, PDE phosphodiesterase, PitA high velocity inner membrane Pi symporter; $c t p A-$ S41 peptidase.

phosphatase activity (Fig. 1B, C). General genomic characteristics for the newly isolated Flavobacterium strains are presented in Table S6. A comprehensive analysis of all the XP datasets are presented in Tables S7-S13. PafA was detected in the Pi-replete and Pi-deplete XPs of all seven (2 non-OSR and 5 OSR) Flavobacterium strains (Blue diamonds, Fig. 4A). Conservation in their response to Pidepletion was also observed (Fig. 4A). This included the abundant expression of proteins associated with the PUSI/II/ III/IV gene clusters, the distinct PhoX and other PME and PDEs (Fig. 4A). However, all Flavobacterium strains displayed microheterogeneity in their response to Pi-depletion. Most notably, this included the expression of phylogenetically distinct PusCD complexes, located within distinct PUS gene clusters (described in detail below) as well as the expression of strain-specific gene clusters.

This fine-scale heterogeneity in their response to $\mathrm{Pi}$ depletion was also apparent in their genomic make up (Fig. 4B). In comparison to ORFs corresponding to core 
(A)

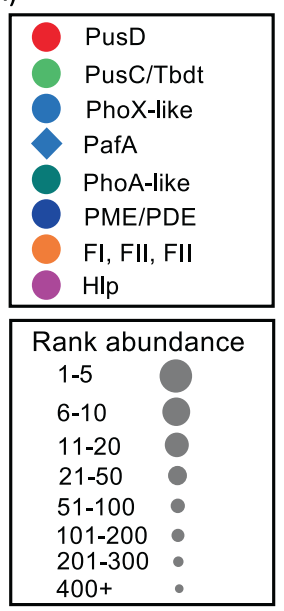

(B)
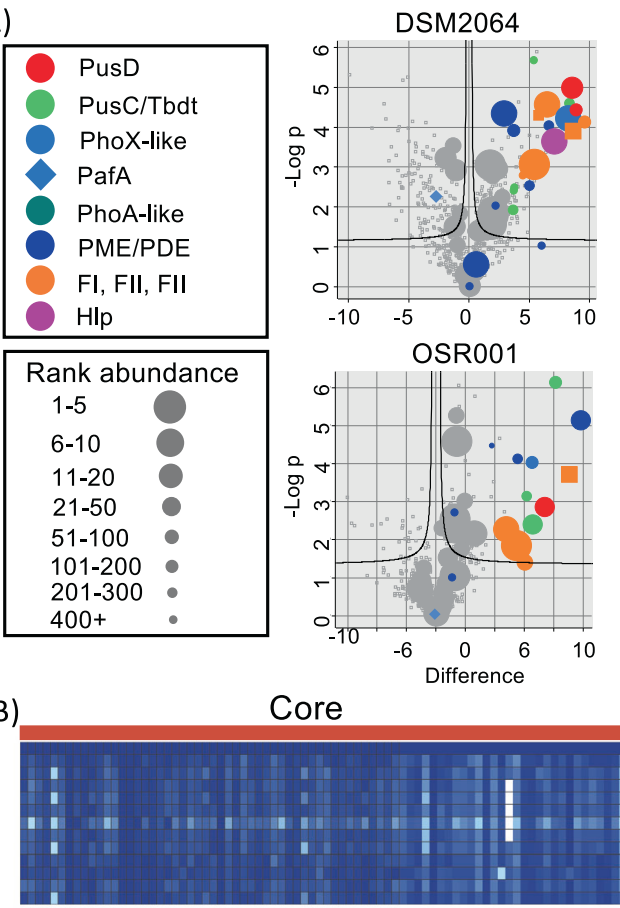

OSR001
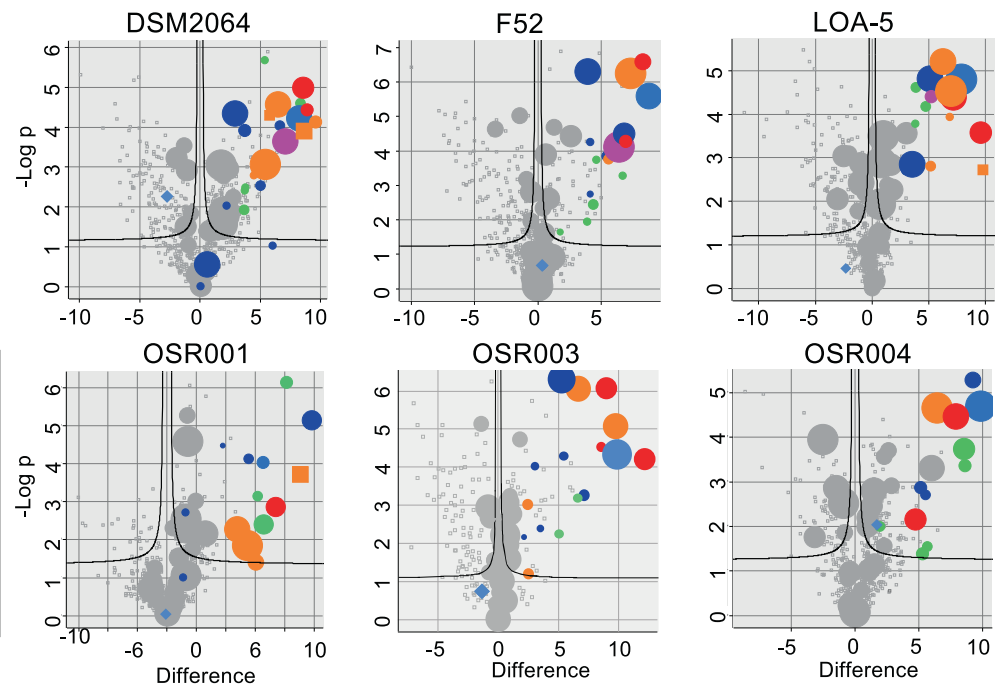

OSR004

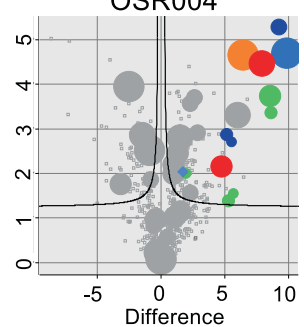

$\mathrm{PHO}$

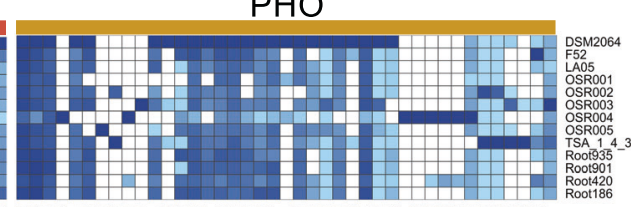

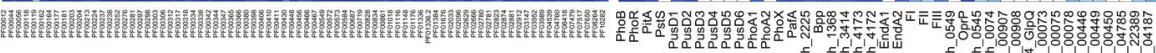

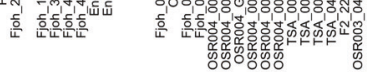

100
90

Identity (\%)

Fig. 4 Identification of P-acquisition proteins and their corresponding loci in several plant-associated Flavobacterium strains. A Volcano plots of exoproteome data illustrating both the difference in the $\log _{2}$ label-free quantitative values (LFQ) intensity between Pireplete and Pi-deplete treatments and the log probability of the observed difference. Dashed lines represent the threshold for significant $P$ values adjusted using $\mathrm{FDR}=0.03$ ( $Q$ values). The rank abundance of each protein is denoted by dot size. The top 30 proteins detected in the Pi-deplete exoproteomes are highlighted. In addition, the rank abundance of predicted P-acquisition proteins is also given. Data points represent the means of triplicate cultures sampled from each growth condition. Abbreviations: PusD phosphate utilisation system-like outer membrane binding domain, PhoX alkaline phosphatase PhoX-like, PusC/Tbdt including TonB-dependent transporter proteins, APases putative phosphatases, FI FII, FIII, hypothetical exoproteins that share weak homology with pectate lyases/polygalacturonases, PafA Pi-irrepressible phosphatase, Hlp hypothetical lipoprotein located in phoBR operon. B Occurrence and similarity ( $\%$ identity) of ORFs related to core/housekeeping processes (maroon) and P-acquisition (gold) amongst the Flavobacterium strains. C Box-whisker plots illustrating the mean identity of core and P-acquisition (PHO) ORFs. Red dots denote outliers. metabolic and housekeeping genes ( $\sim 80$ single-copy representatives), ORFs corresponding to low-Pi-inducible genes had fewer occurrences and greater sequence divergence across the strains (Fig. 4B). The average sequence identity of PHO regulon ORFs (77.9\%) was significantly lower (Wilcox test, $P<0.001$ ) than the average sequence identity of the core ORFs (95.9\%) (Fig. 4C).

\section{Highly expressed PHO regulon genes occur more frequently in plant-associated Bacteroidetes genomes}

We further investigated the occurrence and diversity of these P-acquisition genes across the Flavobacteriaceae family. One hundred two genomes (predominantly from the genus Flavobacterium) previously deposited in the IMG/ JGI database, representing strains isolated from different environmental niches (using 'Ecosystem Type'; 'Study name'; 'Habitat') were selected and analysed (Table S14). This included plant-associated, soil (terrestrial), marine (aquatic, sediment), freshwater (aquatic, sediment), fish (marine host-associated) and various 'other' microhabitats (wastewater treatment, etc.). The number of newly identified P-acquisition genes occurring in the plant-associated genomes was significantly greater (Wilcox test, $P=$ 0.00079 ) than the number occurring in non-plant-associated genomes (Fig. 5A). This equated to greater similarity in the P-scavenging repertoire between plant-associated strains compared to non-plant-associated strains (Fig. 5B). Almost all plant-associated strains were found within a single subclade (subclade 1, Fig. 5C) demonstrating phylogeny contributed towards the occurrence of the newly identified Pi-acquisition genes within their genomes (Fig. 5C). However, niche adaptation was clearly a strong underlying 
(A)

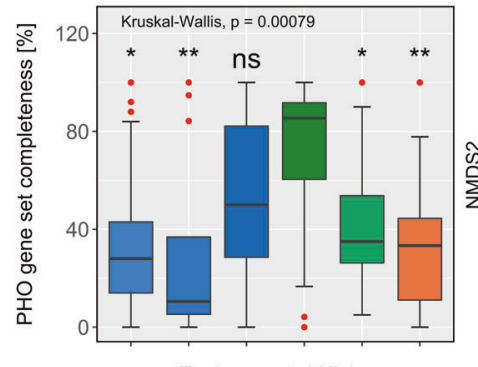

Environmental Niche
(B)

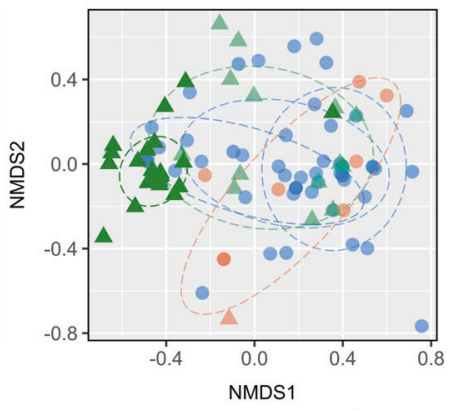

(C) Tree scale: 0.1

\begin{tabular}{|ll|}
\hline Environmental Niche & biome \\
Freshwater & Aquatic \\
Seawater & \\
Fish & \\
Plant & \\
Soil & \\
Other & \\
\hline
\end{tabular}

(D)

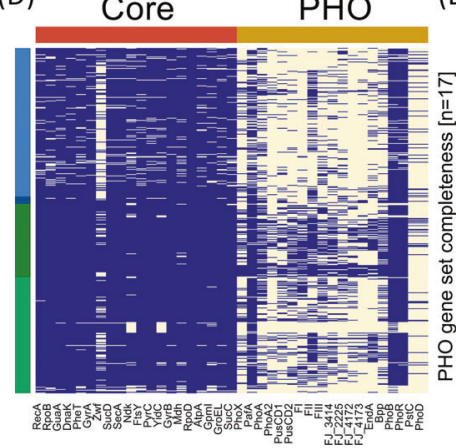

(E)

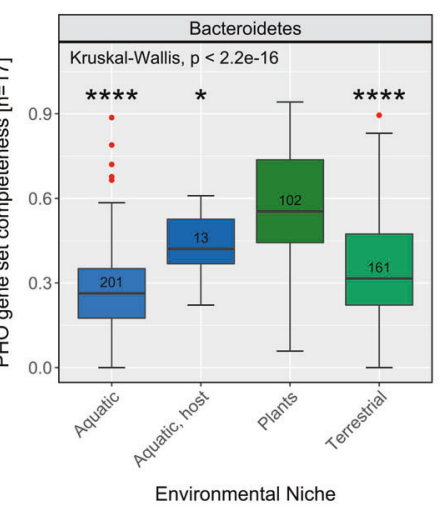

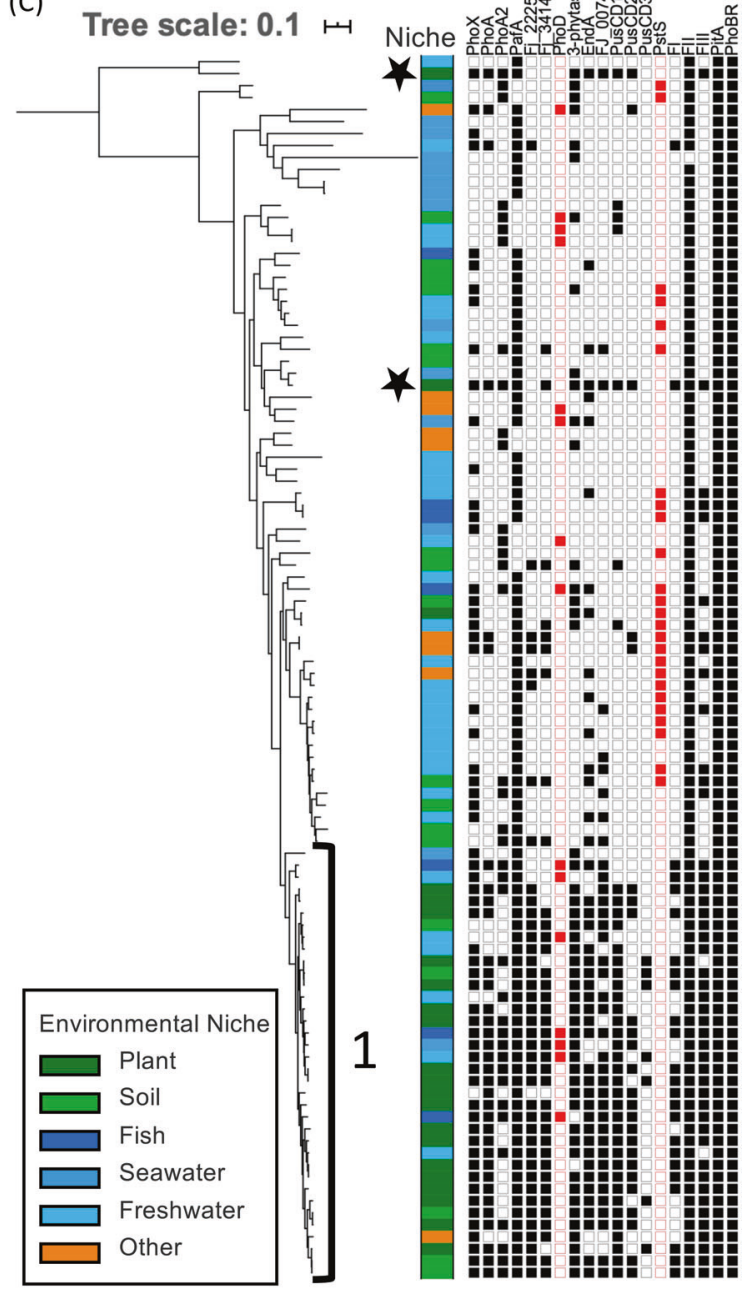

Fig. 5 Occurrence of P-acquisition (PHO) genes in the genomes of plant-associated and non-plant-associated Bacteroidetes strains. A Occurrence of all PHO genes among the 102 Flavobacterium strains. Red dots denote outliers in the data and asterisks denote significance levels (Kruskal Wallis; $*<0.05, * *<0.01, * * *<0.001$ ) for differences of occurrence in each group relative to the Plant-associated group. B Non-metric multidimensional scaling (Bray-Curtis distances) of P-acquisition gene content among the 102 Flavobacterium strains. Ellipses represent euclidean distances from the centre of groups (level $=0.7)$. C The multi-loci maximum-likelihood consensus tree was inferred from a simultaneous comparison of 10 housekeeping and core genes present in 102 Flavobacterium isolates. Tree topology and branch lengths were calculated by maximum likelihood using the VT
$+\mathrm{F}+\mathrm{R} 5$ model of evolution for amino acid sequences based on 1022 sites in 1Q-TREE software [48]. The presence (filled symbol) or absence (hollow symbol) of selected P-acquisition genes is displayed. PstS and PhoD are highlighted in red. Subclade 1 is denoted by the numeric. Stars represent phylogenetically distinct plant-associated strains. D Occurrence of core and PHO genes among 468 Bacteroidetes strains isolated from the five environmental niches. E Occurrence of all PHO genes, excluding PitA and PhoBR, among the 468 Bacteroidetes strains. Red dots denote outliers in the data and asterisks denote significance levels (Kruskal Wallis; $*<0.05, \quad * *<0.01$, $* * *<0.001)$ for differences of occurrence in each group relative to the Plant-associated group. driver as two plant-associated strains, Flavobacterium sp. B17 and Flavobacterium chilense DSM24724, that were distantly related to subclade 1 , still possessed a high number of P-acquisition genes (black stars, Fig. 5C). Interestingly, ORFs corresponding to the constitutive APase PafA, were found in 90/102 strains suggesting that constitutive phosphatase expression is not confined to plant-associated strains only. The occurrence of the well-known APase phoD (15/102) was mostly associated with aquatic strains (13/15). pstS (26/102) was absent from subclade 1 and only found in one plant-associated strain (OSR_004) and this was coincident with a lack of pusCDI, and to a lesser extent pusCD2 (Table S14).

Given the niche-associated diversity of PHO regulon genes within the Flavobacterium genus, we expanded our comparative genomics analysis across the entire Bacteroidetes phylum, still focusing on isolates retrieved from either plant, soil (terrestrial), freshwater or seawater (aquatic), or host-associated strains of aquatic organisms, such as algae or fish (aquatic, host) $(n=468$, Table S15). Anaerobic 


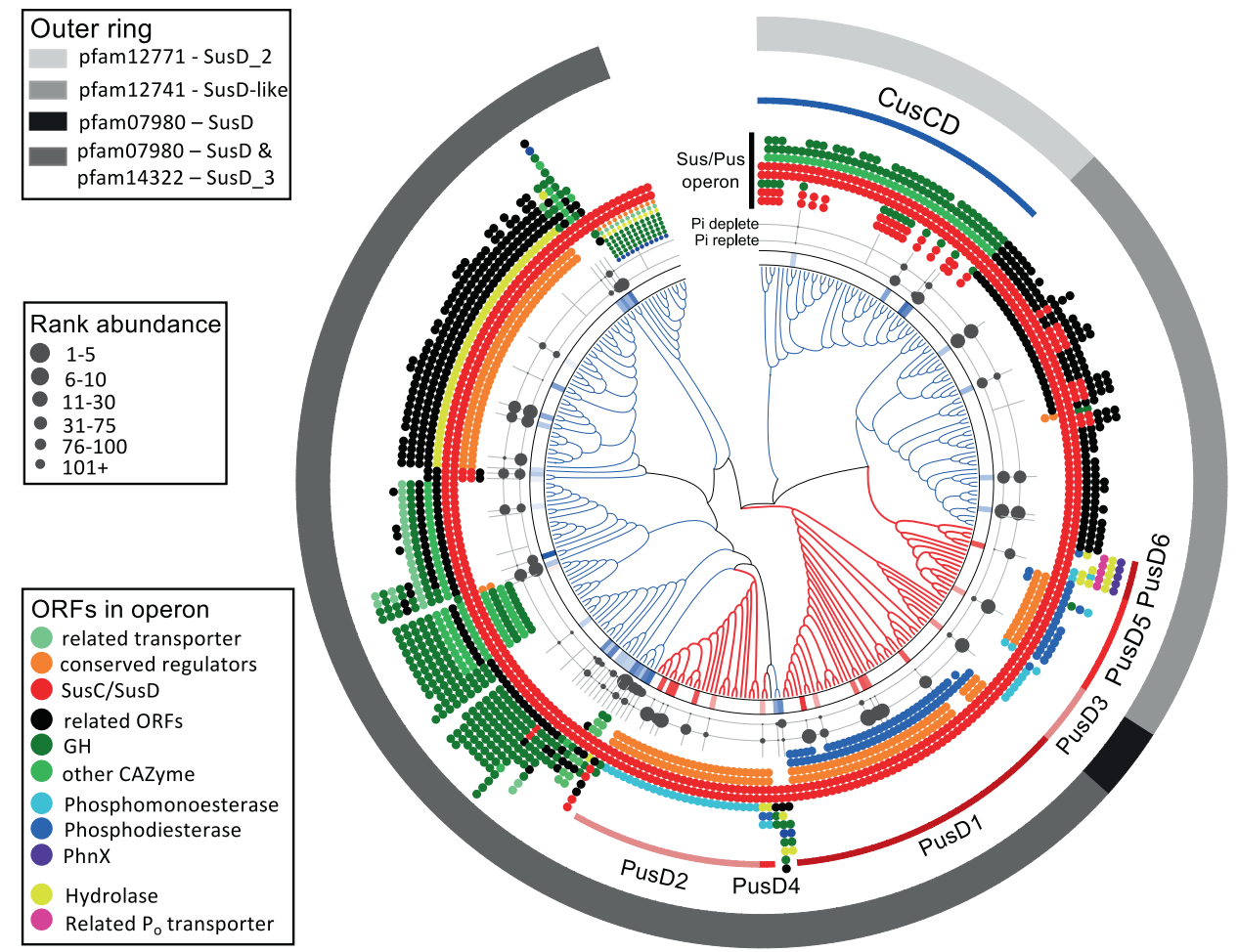

Fig. 6 Phylogenetic, expression and genomic relationship analyses of SusD-like homologues in Flavobacterium. The maximumlikelihood consensus tree was inferred from a simultaneous comparison of 310 protein sequences related to the SusD lipoprotein. Tree topology and branch lengths were calculated by maximum likelihood using the $\mathrm{VT}+\mathrm{F}+\mathrm{R} 5$ model of evolution for amino acid sequences based on 1022 sites in 1Q-TREE software [48]. Clades containing lowPi responsive PusD proteins are coloured red whilst clades containing Pi-insensitive SusD-like proteins are coloured blue. The first ring

isolates inhabiting animal and human gut microbiomes were not scrutinised. The greater heterogeneity in the occurrence of PHO genes versus the core genes was maintained at the phylum level (Fig. 5D), which again resulted in a significantly greater $\left(P<2.2^{\mathrm{e}-16}\right)$ number of PHO genes occurring in plant-associated genomes compared to all nonplant-associated genomes (Fig. 5E). Finally, whilst the average occurrence of $\mathrm{PHO}$ regulon genes across the phylum was $35.2 \pm 25 \%$, the occurrence of genes encoding the constitutive APase PafA was much greater $(78.7 \%)$. This suggests, the ubiquitous PafA- dependent constitutive phosphatase expression observed in plant-associated strains here, is a common trait in this phylum.

\section{Plant-associated Flavobacterium have evolved a distinct set of SusCD-like complexes to facilitate Pi-scavenging}

In total, we detected the expression of six distinct PusCD complexes across the eight Flavobacterium strains expresses the difference in abundance (Pi-deplete: Pi-replete) for all detected SusD-like domains. The second (Pi-replete) and third (Pideplete) rings represent the rank abundance against all proteins for detected SusD-like proteins in the various exoproteomes. The genetic neighbourhoods for each SusC/D-like complex are illustrated by the coloured dot plots. Numericals 1-6 denotes the six PusD forms identified in this study. CusCD denotes the experimentally characterised chitin utilisation system [25]. The outer ring defines the pfam domains associated with each SusD form (predicted by IMG/JGI).

(Fig. 4A). All strains also expressed several Pi-insensitive SusCD-like complexes, in agreement with their predicted specialisation in plant glycan degradation [18] (Table S3). To compare the phylogeny of these Pi-sensitive and Piinsensitive SusCD-like complexes, the SusD-like domains from all complexes detected in the Flavobacterium XPs were aligned (Fig. 6). In addition, the corresponding PusD/ SusD-like homologues from the 102 Flavobacterium genomes were also included. The various PusD and SusD-like forms made up three distinct subclades evidenced by their different pfam domains (Fig. 6, outer ring). PusD was polyphyletic among various SusD-like subclades indicating multiple evolutionary events occurred during the generation of the various PusCD complexes. However, the predicted gene clusters containing the six PusCD forms were clearly distinct from the Pi-insensitive SusCD-like gene clusters. SusCD-like complexes were co-localised predominantly with carbohydrate processing enzymes, whilst all six PusCD complexes, as already described for PUSI and PUSII in DSM2064, were co-localised with PMEs, PDEs, 
as well as phosphonate-degrading enzymes and inner membrane $\mathrm{P}_{\mathrm{o}}$ transporters (Fig. 6). All PusCD-containing PUS gene clusters differed, suggesting a distinct role in $\mathrm{P}_{\mathrm{O}^{-}}$ acquisition for each. PUSI, containing PusCD1, and the two predicted periplasmic PDEs, was the most common PUS system found in Flavobacterium revealing these loci likely play an important role in scavenging ubiquitous phosphodiesters (most likely lipid headgroups and nucleic acids) found in the soil/rhizosphere.

\section{Discussion}

Competition for $\mathrm{P}$ in the rhizosphere is incredibly intense [30, 34]. Hence, understanding how Bacteroidetes competes for this scarce nutrient provides valuable insights into the underlying molecular mechanisms responsible for this phylum being a dominant member of the plant microbiome $[1-3,8]$. This study provides strong evidence that plantassociated Bacteroidetes possess an incredibly high potential for transforming $\mathrm{P}_{\mathrm{o}}$ to bioavailable $\mathrm{Pi}$. This includes the apparent identification of novel molecular mechanisms for $\mathrm{P}$ uptake linked to TonB-dependent transport [58] that differ from previously known bacterial $\mathrm{P}$ transport mechanisms [13].

The constitutive PME expression displayed by all $\mathrm{Bac}$ teroidetes OSR isolates irrespective of $\mathrm{Pi}$ concentrations (Fig. 1) is a unique and potentially important trait in the context of improving plant phosphorus uptake at the root-soil interface [33, 39, 59]. Whilst inducible PME activity is high when Pseudomonas spp. are grown on succinate (growth medium $\mathrm{pH} 7-8$ ) [15, 50], a lower $\mathrm{pH}$ range $(\mathrm{pH} 5-7)$ in the growth medium used here drastically inhibited their PME activity. Thus, Flavobacterium spp. may outperform traditional alkaline phosphatase-harbouring rhizobacteria, including Pseudomonas spp. [13-16], with respect to $\mathrm{P}$-mobilisation, in an agricultural setting where rhizosphere $\mathrm{pH}$ is typically $\mathrm{pH} 5.5-7.5$ [32]. This hypothesis warrants further investigation through protein purification and in planta experiments.

Plant-associated Flavobacterium expressed a far greater number of PMEs and PDEs than other well-known rhizobacteria [13-16] and not all were silenced by high concentrations of Pi (Table 1). Importantly, the majority of these P-acquisition loci appear to be niche-adapted traits that would allow plant-associated Bacteroidetes to overcome competition for $\mathrm{P}$ in the rhizosphere, where labile $\mathrm{Pi}$ is depleted and replaced by immobilised $\mathrm{P}_{\mathrm{o}}$ [32, 37]. The Flavobacterium PhoX is a prime example of this niche adaptation to the plant microbiome. This phosphatase was one of the major proteins secreted by all plant-associated Flavobacterium strains in response to Pi-depletion (Fig. 4) but is only a common genetic feature in the genomes of plant-associated Bacteroidetes strains. PhoX is a lipoprotein [60], hence we did not detect this in our soluble fractions (Fig. S6). However, given its predicted localisation in the $\mathrm{OM}$ and structural similarity to other characterised PhoX homologues that are responsible for PME activity in other rhizobacteria [16, 47, 60,61], we predict this enzyme is responsible for most of the elevated inducible PME activity observed in our Flavobacterium strains. Flavobacterium PhoX is both phylogenetically and structurally distinct from previously characterised PhoX and can be further subdivided into three subclades (Fig. S4). Each subclade is predicted to possess a different active site architecture and surface potential compared to the characterised PhoX [61] (Fig. S3), which may explain why Flavobacterium inducible activity is more resilient to lower $\mathrm{pH}$ conditions compared to Pseudomonas [15, 50].

In contrast, the widespread occurrence of PafA in Bacteroidetes isolated from all environmental niches reveals that the unusual constitutive phosphatase expression is almost certainly a common phenotypic trait in this phylum. PafA, whose expression was constant in all eight strains, is a Pi-irrepressible phosphatase that is a unique member of the alkaline phosphatase superfamily whose $\mathrm{pH}$ optimum is neutral to slightly acidic and also possesses diesterase activity [53, 55]. Using DSM2064 as the model, PafA was the major protein detected in one of the phosphatase-active protein fractions (Fig. S6), strongly suggesting this enzyme contributes towards the unique constitutive and inducible PME activity in our Flavobacterium isolates.

Why Bacteroidetes have such a huge diversity of TBDTs and SusCD-like complexes is a recurrent question [5, 22, 58]. Here, we present evidence that suggests novel OM transporters related to those traditionally associated with siderophore and oligosaccharide transport [20-25, 55, 62] may be involved in transporting $\mathrm{P}_{\mathrm{o}}$ species. All plant-associated Bacteroidetes lack common organic phosphorus transporters and the high affinity PstSABC transporter for Pi $[13,15]$, but instead possess novel low-Piinducible PusCD complexes and orphan TBDTs, indicating Bacteroidetes favour an alternative mechanism for competitively acquiring P. Given, the pore size of transmembrane TBDTs and SusC-like domains and general role as polysaccharide transporters [19, 58], their co-localisation with ORFs encoding co-expressed predicted periplasmic PME and PDEs (Fig. 6) strongly suggests these transporters have evolved to target $\mathrm{P}_{\mathrm{o}}$. The co-localisation of a low-Piinducible TBDTs with 3-phytase (Fjoh_1368), a wellknown $\mathrm{P}_{\mathrm{O}}$-degrading enzyme [63] supports this hypothesis. Further support is provided by the abundant expression of the uncharacterised FI and FII, located in PUSIII and PUSIV, that both share sequence homology with an uncharacterised PHO regulon lipoprotein in C. crescentus [56] as well as structural homology with plant-cell wall 
degradation enzymes [57]. Thus, when facing Pi-depletion, Flavobacterium may target the large reservoir of $\mathrm{P}_{0}$ associated with plant root cell walls [64] and the consequence of this unique mechanism warrants further investigation.

Marine and Gut Bacteroidetes predominantly acquire carbohydrate substrates through a 'selfish uptake' mechanism using SusCD-like harbouring PULs [24, 65]. This selfish mechanism for degrading more recalcitrant organic carbon does not liberate low molecular weight carbon for scavengers in the way the 'sharing' mechanisms (extracellular enzyme secretion) can [65]. We have recently demonstrated 'sharing' of more recalcitrant $\mathrm{P}_{\mathrm{o}}$ substrates occurs in Pseudomonas spp. through the production of periplasmic and extracellular phosphatases [50]. Based on the data presented here, Flavobacterium may be capable of both a sharing and selfish mechanism of $\mathrm{P}_{\mathrm{o}}$-utilisation that is partially dependent on external $\mathrm{Pi}$ concentrations, which may have divergent outcomes for rhizosphere $\mathrm{P}$ cycling.

\section{Conclusions}

$\mathrm{P}_{\mathrm{o}}$ often represents a major fraction of the total $\mathrm{P}$ content in both agricultural and non-agricultural soils $[59,66]$. This is set to rise with the increased use of organic $\mathrm{P}$ fertilisers primarily from manure and other waste materials [31, 59]. Our finding that abundant resident microorganisms of many cropping systems potentially possess novel mechanisms for liberating Pi from $P_{o}$ may influence sustainable approaches to crop production and combat the global phosphorus crisis $[24,29,34,59]$. Whether these novel and unique molecular mechanisms discovered in Bacteroidetes result in an enhanced or broader capability to degrade rhizosphereassociated $\mathrm{P}_{\mathrm{o}}$ is still an open question, but one which has important consequences for sustainable agriculture. Not only for enhancing phosphorus acquisition in crops, but also developing 'designer rhizospheres' through selection, using plant genotyping and environmental conditioning, to enhance plant functionality, such as plant immunity or bioremediation [67]. This study paves the way for further exciting research on the P physiology of Flavobacterium strains and their potential exploitation as microbial tools in sustainable agriculture.

\section{Data availability}

The proteomics datasets supporting the conclusions of this article are available in the ProteomeXchange Consortium via the PRoteomics IDEntifications (PRIDE) partner repository with the dataset identifier PXD014380 and 10.6019/ PXD014380. The transcriptomics dataset supporting the conclusions of this article are available in the NCBI short read archive (SRA) repository with the dataset identifier Bioproject accession PRJNA635152.
Acknowledgements We thank the Warwick Proteomics Research Facility, namely Dr. Cleidiane Zampronio and Dr. Juan Hernandez Fernaud for their assistance in generating and processing the massspectrometry data. We also thank Dr. Eddie Cytryn for kindly sending us various strains and plasmids used in this study. This study was funded by the Biotechnology and Biological Sciences Research Council (BBSRC) under the project codes BB/L026074/1 and BB/ T009152/1 linked to The Soil and Rhizosphere Interactions for Sustainable Agri-ecosystems (SARISA) programme and a Discovery Fellowship (IL), respectively.

\section{Compliance with ethical standards}

Conflict of interest The authors declare that they have no conflict of interest.

Publisher's note Springer Nature remains neutral with regard to jurisdictional claims in published maps and institutional affiliations.

Open Access This article is licensed under a Creative Commons Attribution 4.0 International License, which permits use, sharing, adaptation, distribution and reproduction in any medium or format, as long as you give appropriate credit to the original author(s) and the source, provide a link to the Creative Commons license, and indicate if changes were made. The images or other third party material in this article are included in the article's Creative Commons license, unless indicated otherwise in a credit line to the material. If material is not included in the article's Creative Commons license and your intended use is not permitted by statutory regulation or exceeds the permitted use, you will need to obtain permission directly from the copyright holder. To view a copy of this license, visit http://creativecommons. org/licenses/by/4.0/.

\section{References}

1. Bulgarelli D, Rott M, Schlaeppi K, Ver Loren van Themaat E, Ahmadinejad N, Assenza F, et al. Revealing structure and assembly cues for Arabidopsis root-inhabiting bacterial microbiota. Nature. 2012;488:91-5.

2. Bulgarelli D, Garrido-Oter R, Münch Philipp C, Weiman A, Dröge J, Pan Y, et al. Structure and function of the bacterial root microbiota in wild and domesticated barley. Cell Host Microbe. 2015; 17:392-403.

3. Niu B, Paulson JN, Zheng X, Kolter R. Simplified and representative bacterial community of maize roots. PNAS. 2017;114: e2450-9.

4. Teeling H, Fuchs BM, Becher D, Klockow C, Gardebrecht A, Bennke CM, et al. Substrate-controlled succession of marine bacterioplankton populations induced by a phytoplankton bloom. Science. 2012;336:608-11.

5. Thomas F, Hehemann J-H, Rebuffet E, Czjzek M, Michel G. Environmental and gut Bacteroidetes: the food connection. Front Microbiol. 2011;2:93.

6. Yin C, Hulbert SH, Schroeder KL, Mavrodi O, Mavrodi D, Dhingra A, et al. Role of bacterial communities in the natural suppression of Rhizoctonia solani bare patch disease of wheat (Triticum aestivum L.). Appl Environ Microbiol. 2013;79: 7428-38.

7. Gardner T, Acosta-Martinez V, Senwo Z, Dowd SE. Soil rhizosphere microbial communities and enzyme activities under organic farming in Alabama. Diversity. 2011;3:308-28.

8. Kolton M, Erlacher A, Berg G, Cytryn E. The Flavobacterium genus in the plant holobiont: ecological, physiological, and applicative insights. In: Castro-Sowinski S, editor. Microbial models: 
from environmental to industrial sustainability. Singapore: Springer Singapore; 2016. p. 189-207.

9. Maimaiti J, Zhang Y, Yang J, Cen Y-P, Layzell DB, Peoples M, et al. Isolation and characterization of hydrogen-oxidizing bacteria induced following exposure of soil to hydrogen gas and their impact on plant growth. Environ Microbiol. 2007;9:435-44.

10. Kwak M-J, Kong HG, Choi K, Kwon S-K, Song JY, Lee J, et al. Rhizosphere microbiome structure alters to enable wilt resistance in tomato. Nat Biotechnol. 2018;36:1117.

11. Nishioka T, Marian M, Kobayashi I, Kobayashi Y, Yamamoto K, Tamaki H, et al. Microbial basis of Fusarium wilt suppression by Allium cultivation. Sci Rep. 2019;9:1715.

12. Johansen JE, Binnerup SJ. Contribution of Cytophaga-like bacteria to the potential turnover of carbon, nitrogen, and phosphorus by bacteria in the rhizosphere of barley (Hordeum vulgare L.). Microb Ecol. 2002;43:298-306.

13. Santos-Beneit F. The Pho regulon: a huge regulatory network in bacteria. Front Microbiol. 2015;6:402.

14. Antelmann H, Scharf C, Hecker M. Phosphate starvationinducible proteins of Bacillus subtilis: proteomics and transcriptional analysis. J Bacteriol. 2000;182:4478-90.

15. Lidbury IDEA, Murphy ARJ, Scanlan DJ, Bending GD, Jones AME, Moore JD. et al. Comparative genomic, proteomic and exoproteomic analyses of three Pseudomonas strains reveals novel insights into the phosphorus scavenging capabilities of soil bacteria. Environ Microbiol. 2016;18:3535-49.

16. Zaheer R, Morton R, Proudfoot M, Yakunin A, Finan TM. Genetic and biochemical properties of an alkaline phosphatase PhoX family protein found in many bacteria. Environ Microbiol. 2009;11:1572-87.

17. Bauer M, Kube M, Teeling H, Richter M, Lombardot T, Allers E, et al. Whole genome analysis of the marine Bacteroidetes 'Gramella forsetii' reveals adaptations to degradation of polymeric organic matter. Environ Microbiol. 2006;8:2201-13.

18. Kolton M, Sela N, Elad Y, Cytryn E. Comparative genomic analysis indicates that niche adaptation of terrestrial flavobacteria is strongly linked to plant glycan metabolism. PLoS ONE. 2013;8: e76704.

19. Martens EC, Koropatkin NM, Smith TJ, Gordon JI. Complex glycan catabolism by the human gut microbiota: the Bacteroidetes Sus-like paradigm. J Biol Chem. 2009;284:24673-7.

20. Glenwright AJ, Pothula KR, Bhamidimarri SP, Chorev DS, Baslé A, Firbank SJ, et al. Structural basis for nutrient acquisition by dominant members of the human gut microbiota. Nature. 2017; 541:407-11.

21. Foley MH, Cockburn DW, Koropatkin NM. The Sus operon: a model system for starch uptake by the human gut Bacteroidetes. Cell Mol Life Sci. 2016;73:2603-1.

22. Kappelmann L, Krüger K, Hehemann J-H, Harder J, Markert S, Unfried F, et al. Polysaccharide utilization loci of North Sea Flavobacteriia as basis for using SusC/D-protein expression for predicting major phytoplankton glycans. ISME J. 2019;13:76-91.

23. Zhu Y, Thomas F, Larocque R, Li N, Duffieux D, Cladière L, et al. Genetic analyses unravel the crucial role of a horizontally acquired alginate lyase for brown algal biomass degradation by Zobellia galactanivorans. Environ Microbiol. 2017;19:2164-81.

24. Cuskin F, Lowe EC, Temple MJ, Zhu Y, Cameron EA, Pudlo NA, et al. Human gut Bacteroidetes can utilize yeast mannan through a selfish mechanism. Nature 2015;517:165-9.

25. Larsbrink J, Zhu Y, Kharade SS, Kwiatkowski KJ, Eijsink VGH, Koropatkin NM, et al. A polysaccharide utilization locus from Flavobacterium johnsoniae enables conversion of recalcitrant chitin. Biotechnol Biofuels. 2016;9:2.

26. Cordell D, Drangert J-O, White S. The story of phosphorus: global food security and food for thought. Glob Environ Change. 2009;19:292-305.
27. Tyrrell T. The relative influences of nitrogen and phosphorus on oceanic primary production. Nature 1999;400:525-31.

28. Filippelli GM. The global phosphorus cycle: past, present, and future. Elements. 2008;4:89-95.

29. Yang N, Zavišić A, Pena R, Polle A. Phenology, photosynthesis, and phosphorus in European beech (Fagus sylvatica L.) in two forest soils with contrasting P contents. J Plant Nutr Soil Sci. 2016;179:151-8.

30. Goll DS, Brovkin V, Parida BR, Reick CH, Kattge J, Reich PB, et al. Nutrient limitation reduces land carbon uptake in simulations with a model of combined carbon, nitrogen and phosphorus cycling. Biogeosciences. 2012;9:3547-69.

31. Cordell D, White S. Tracking phosphorus security: indicators of phosphorus vulnerability in the global food system. Food Security. 2015;7:337-50.

32. White PJ, Hammond JP. Phosphorus nutrition of terrestrial plants. In: White PJ, Hammond JP, editors. The ecophysiology of plantphosphorus interactions. Dordrecht: Springer Netherlands; 2008. p. $51-81$.

33. Sharma SB, Sayyed RZ, Trivedi MH, Gobi TA. Phosphate solubilizing microbes: sustainable approach for managing phosphorus deficiency in agricultural soils. SpringerPlus. 2013;587.

34. Turner BL, Papházy MJ, Haygarth PM, McKelvie ID. Inositol phosphates in the environment. Philos Trans R Soc Lond B Biol Sci. 2002;357:449-69.

35. Schachtman DP, Reid RJ, Ayling SM. Phosphorus uptake by plants: from soil to cell. Plant Physiol. 1998;116:447-53.

36. Zou X, Binkley D, Doxtader KG. A new method for estimating gross phosphorus mineralization and immobilization rates in soils. Plant Soil. 1992;147:243-50.

37. Zoysa AKN, Loganathan P, Hedley MJ. A technique for studying rhizosphere processes in tree crops: soil phosphorus depletion around camellia (Camellia japonica L.) roots. Plant Soil. 1997; 190:253-65.

38. Shen J, Yuan L, Zhang J, Li H, Bai Z, Chen X, et al. Phosphorus dynamics: from soil to plant. Plant Physiol. 2011;156:997-1005.

39. Stutter MI, Shand CA, George TS, Blackwell MSA, Bol R, MacKay RL, et al. Recovering phosphorus from soil: a root solution? Environ Sci Technol. 2012;46:1977-8.

40. Wanner BL. Phosphorus assimilation and its control of gene expression in Escherichia coli. In: Hauska G, Thauer R, editors. The molecular basis of bacterial metabolism. Colloquium der Gesellschaft für Biologische Chemie 5.-7.1990. Mosbach/Baden: Springer Berlin Heidelberg; 1990. p. 152-63.

41. Gandhi NU, Chandra SB A comparative analysis of three classes of bacterial non-specific acid phosphatases and archaeal phosphoesterases: evolutionary perspective. Acta Inform Med. 2012;20:167-73.

42. IDEA Lidbury, Fraser T, Murphy ARJ, Scanlan DJ, Bending GD, AME Jones, et al. The 'known' genetic potential for microbial communities to degrade organic phosphorus is reduced in low-pH soils. Microbiol Open. 2017;6:e00474.

43. Kolton M, Green SJ, Harel YM, Sela N, Elad Y, Cytryn E. Draft genome sequence of Flavobacterium sp. strain F52, isolated from the rhizosphere of Bell Pepper (Capsicum annuum L. cv. Maccabi). J Bacteriol. 2012;194:5462-3.

44. McBride MJ, Kempf MJ. Development of techniques for the genetic manipulation of the gliding bacterium Cytophaga johnsonae. J Bacteriol. 1996;178:583-90.

45. Nishioka T, Elsharkawy MM, Suga H, Kageyama K, Hyakumachi M, Shimizu M. Development of culture medium for the isolation of Flavobacterium and Chryseobacterium from rhizosphere soil. Microbes Environ. 2016;31:104-10.

46. Gil R, Silva FJ, Peretó J, Moya A. Determination of the core of a minimal bacterial gene set. Microbiol Mol Biol Rev. 2004;68:518-37.

47. Seemann T. Prokka: rapid prokaryotic genome annotation. Bioinformatics 2014;30:2068-9. 
48. Minh BQ, Schmidt HA, Chernomor O, Schrempf D, Woodhams MD, von Haeseler A, et al. IQ-TREE 2: New models and efficient methods for phylogenetic inference in the genomic era. Mol Biol Evol. 2020;37:1530-4.

49. Roca A, Pizarro-Tobías P, Udaondo Z, Fernández M, Matilla MA, Molina-Henares MA, et al. Analysis of the plant growth-promoting properties encoded by the genome of the rhizobacterium Pseudomonas putida BIRD-1. Environ Microbiol. 2013;15:780-94.

50. IDEA Lidbury, Murphy ARJ, Fraser TD, et al. Identification of extracellular glycerophosphodiesterases in Pseudomonas and their role in soil organic phosphorus remineralisation. Sci Rep. 2017;7:2179. JD, et al.

51. Brickman E, Beckwith J. Analysis of the regulation of Escherichia coli alkaline phosphatase synthesis using deletions and $\varphi 80$ transducing phages. J Mol Biol. 1975;96:307-15.

52. Skouri-Panet F, Benzerara K, Cosmidis J, Férard C, Caumes G, De Luca $\mathrm{G}$, et al. In vitro and in silico evidence of phosphatase diversity in the biomineralizing bacterium Ramlibacter tataouinensis. Front Microbiol. 2018;8:2592.

53. Berlutti F, Passariello C, Selan L, Thaller MC, Rossolini GM. The Chryseobacterium meningosepticum PafA enzyme: prototype of a new enzyme family of prokaryotic phosphate-irrepressible alkaline phosphatases? Microbiology. 2001;147:2831-9.

54. Lombard V, Golaconda Ramulu H, Drula E, Coutinho PM, Henrissat B. The carbohydrate-active enzymes database (CAZy) in 2013. Nucleic Acids Res. 2014;42:D490-5.

55. Sunden F, AlSadhan I, Lyubimov AY, Ressl S, Wiersma-Koch H, Borland $\mathrm{J}$, et al. Mechanistic and evolutionary insights from comparative enzymology of phosphomonoesterases and phosphodiesterases across the alkaline phosphatase superfamily. J Am Chem Soc. 2016;138:14273-87.

56. Le Blastier S, Hamels A, Cabeen M, Schille L, Tilquin F, Dieu M, et al. Phosphate starvation triggers production and secretion of an extracellular lipoprotein in Caulobacter crescentus. PLoS ONE. 2010;5:e14198.
57. Maldonado MC, Strasser, de Saad AM. Production of pectinesterase and polygalacturonase by Aspergillus niger in submerged and solid state systems. J Ind Microbiol Biotechnol. 1998;20:34-8.

58. Bolam DN, van den Berg B. TonB-dependent transport by the gut microbiota: novel aspects of an old problem. Curr Opin Struct Biol. 2018;51:35-43.

59. Haygarth PM, Harrison AF, Turner BL. On the history and future of soil organic phosphorus research: a critique across three generations. Eur J Soil Sci. 2018;69:1

60. Putker F, Tommassen-van Boxtel R, Stork m, Rodríguez-Herva JJ, Koster M, Tommassen J. The type II secretion system (Xcp) of Pseudomonas putida is active and involved in the secretion of phosphatases. Environ Microbiol. 2013;15:2658-71.

61. Yong SC, Roversi P, Lillington J, Rodriguez F, Krehenbrink M, Zeldin $\mathrm{OB}$, et al. A complex iron-calcium cofactor catalyzing phosphotransfer chemistry. Science. 2014;345:1170-3.

62. Joglekar P, Sonnenburg ED, Higginbottom SK, Earle KA, Morland C, Shapiro-Ward S, et al. Genetic variation of the SusC/SusD homologs from a polysaccharide utilization locus underlies divergent fructan specificities and functional adaptation in Bacteroides thetaiotaomicron. mSphere. 2018;3:e0185-18.

63. Lim BL, Yeung P, Cheng C, Hill JE. Distribution and diversity of phytate-mineralizing bacteria. ISME J. 2007;1:321-30.

64. Zhu XF, Wang ZW, Wan JX, Sun Y, Wu YR, Li GX, et al. Pectin enhances rice (Oryza sativa) root phosphorus remobilization. J Exp Bot. 2014;66:1017-24.

65. Reintjes G, Arnosti C, Fuchs BM, Amann R. An alternative polysaccharide uptake mechanism of marine bacteria. ISME J. 2017;11:1640-50.

66. Turner BL, Haygarth PM. Phosphatase activity in temperate pasture soils: Potential regulation of labile organic phosphorus turnover by phosphodiesterase activity. Sci Total Environ. 2005;344:27-36.

67. Sergaki C, Lagunas B, Lidbury I, Gifford ML, Schäfer P. Challenges and approaches in microbiome research: From fundamental to applied. Front Plant Sci. 2018;9:1205. 